water was about seren feet; but, owing to the influence of gales and currents, the whole ocean is filled with pack from fifty to two hundred feet in thickness. During the whole winter this region is subject to violent local gales, which open huge cracks in this frozen ocean, often extending many miles, and from ten to five hundred yards wide. These cracks freeze over very rapidly, as the temperature of the sea-water alway stands at $29.2^{\circ} \mathrm{F}$. We have known two feet and a half of ice to be formed over one of these cracks in ten hours. This expansion, acting like a great wedge, shoves the great masses of pack apart; and it can only find room in the direction of the lower latitudes, or side of the least resistance. Hence we see along the southern edge of the eternal pack a continual crowding-down of old ice, which has yielded to the new ice formed in the cracks, and, in its turn, is packed and displaced; but we never found that there was any accumulation of new ice on the submerged masses of old pack, no matter to what depth they rested in the water. This process going on daily and hourly, the ice over the pole is kept at an even thickness ; the old, heavy ice, often high above the surface, yielding to the new. We never found that ice formed on the bottom of the sea, the lakes, or the rivers.

The migration of the eider occurs in May; and the flight is to the north-east, in the direction of Prince Patrick's Land. 'We never saw any flight of birds to or from true north at any season of the year. 'They commence returning' along the western shore in July, and linger as long as there is any open water.

The members of the expedition found time to make a large collection in ethnology and natural history, which has been turned over to the Smithsonian institution, and is now being catalogued and placed. All records were kept in duplicate, and both copies were brought safely back to the United States. The official report is now being compiled at Washington, and will be issued by the signal-office as soon as published.

The party returned to the United States on the schooner Leo, chartered for that purpose ; leaving the station Aug. 29, 1883, and returned viâ Bering Strait and the Pass of Akutan, landing at San Francisco, Cal., Oct. 7, 1883; touching only at St. Michael's, where Lieut. Schwatka and his party were found waiting for a chance to return to the United States, after their adventurous ride of over two thousand miles down the Yukon on a raft, and at Unalaska, to repair our little vessel, which had been damaged by the ice.

P. H. RAY.

\section{ON THE STATE OF THE INTERIOR OF THE EARTH.}

The appearance of the new edition of Thomson and Tait's treatise on natural philosophy affords an opportunity for geologists to object to conclusions reached by physicists in relation to the condition of the interior of the earth. Various physicists, chief among whom are Hopkins, Sir William Thomson, and G. H. Darwin, have concluded, from a discussion of the phenomena of precession and of tidal friction, that the earth is a solid, with a rigidity at least as great as steel. Some time ago Thomson retracted the first part of the argument, on a suggestion made by Newcomb, and the writer expected to see a retraction of the entire argument in the new edition of the philosophy; but it does not appear. Yet the statement is somewhat modified. On the 485th page of rol. i., part ii., the following paragraph appears : -

"These conclusions, drawn solely from a consideration of the necessary order of cooling and consolidation, according to Bischof's result as to the relative specific gravities of solid and of melted rock, are in perfect accordance with $\S \S 832-848$, regarding the present condition of the earth's interior, - that it is not, as commonly supposed, all liquid within a thin solid crust of from 30 to 100 miles thick, but that it is, on the whole, more rigid, certainly, than a continuous solid globe of glass of the same diameter, and probably than one of steel."

It is not my purpose as a geologist to discuss the methods by which this conclusion is reached; nor shall I array the facts by which geologists arrive at a different conclusion. I propose simply to characterize the lines of inductive reasoning used by them. These are as follows :-

\section{The argument from displacement.}

The writer has carefully studied a fault in Utah and Arizona, about three hundred miles in length, with a throw varying from two thousand to five thousand feet. Everywhere along its course the displacement is easily seen : its verity is a fact of observation, confirmed by the observation of other geologists thoroughly competent. The fault is so plain, that the tyro in geology may see it. Now, in the case of this fault, three hypotheses may be entertained, - first, that the thrown side subsided; second, that the thrown side remained stationary in relation to the centre of the earth, and the opposite side was upheared; or, third, that 
while the thrown side went down, the opposite side went up. To explain the first hypothesis, we must have either a condensation of the mass underlying the thrown side, extending toward the centre of the earth, or a transferrence of the material from immediately beneath the thrown side to some other part of the interior of the earth. A condensation or a transferrence is absolutely necessary. The latter hypothesis is the hypothesis of a fluid interior. In the second case mentioned above, where the side opposite the thrown block is supposed to be upheaved, there must be either an expansion of the immediately underlying material, or a transferrence of material. 'The hypothesis of a vacuum beneath is untenable, for it can be easily demonstrated that the strength of materials could not possibly sustain the resultant stress. We are forced, therefore, to the conclusion that there is either an expansion or a transferrence of material, the latter being equivalent to the hypothesis of an interior fluid. The third case is, that one side went down while the other side went up; and this hypothesis is sustained by many concomitant facts. In this case there must either be a condensation on one side and an expansion on the other, or a transferrence of material : and geologists conclude that there has been a transferrence of material; i.e., they postulate a fluid interior.

Faults like the one above mentioned are not infrequent. Many are discovered of greater magnitude, many more of less ; and, wherever the geology of any great district of country has been explored, such faults have been discovered, so that they are now known to exist in great number's throughout all the studied portion of the land-surface of the earth. Every year's research - it may almost be said every month's or every week's research - adds to the number.

In addition to these faults, geologists are every where discovering flexures, many of them simple monoclinal bendings by which the crust of the earth is displaced; one side being lowered, or the other raised, or the two simultaneously moved. Again : great anticlinal flexures are discovered, sometimes developed to appressed folds, and monoclinal and anticlinal flexures are found throughout the whole known portion of the land-surface of the earth; so that these displacements by faulting and by flexure are widely and generally distributed.

Again : displacement is a phenomenon, not simply of the present time, but of all known geologic time; as like displacements are discovered of various ages, beginning with the oldest archaean, and extending to the present time. Nor can we say that displacement was either greater or less in earlier geologic times than in the present. Such displacements as have been here briefly characterized have occurred again and again in the same district of country, sometimes following the old lines, oftener along new lines, traversing in diverse ways the same territory; so that blocks of the crust that have at one time been upheaved have at another time subsided, and blocks that at one time have subsided have at another been upheaved. It is sometimes possible to discover as many as six or more epochs of alternating displacement; in the first the rocks going up, in the second down, then up, then down, etc. The evidence of repeated displacement in the same district is not simply local, but is widely spread throughout the known portion of the land-surface of the earth.

But the evidence for a fluid condition of the interior, derived from displacement, does not end here. Take first a simple example like the following : a block of stony crust is separated from the adjacent rock on all sides by fracture. Such a block may be many miles in length (ten or a hundred), and of varying width (two or twenty miles). Such a severed block will be found by the geologist to have careened, one side or edge going down while the other came up. In order to explain this displacement, it is necessary to assume that there was an increasing rate of expansion beneath the block from the axis of rotation to the upturned edge, and an increasing condensation of the underlying material from the same axis to the edge of the down-thrown side, or to assume that it careened on a fluid mass. The latter is the explanation accepted by geologists. Again : such a block may be broken into many parts, each one of which behaves as an inte-. ger, and careens on its own axis. Many snck careened blocks have been discovered, though this particular form of displacement has not been described by geologists to the extent of those mentioned above.

\section{The argument from vulcanism.}

Fluid matter comes up from unknown depths, and is sometimes intercalated between horizontal or dipping beds of sedimentary rock; but oftener it comes to the surface and is poured out in sheets, sheet being piled on sheet until mountains and mountain systems are produced. The amount of matter thus brought up from below is great; and it occupies largo 
areas throughout all the known portion of the earth, forming the substance of many mesas, plateaus, and mountain systems, in which valleys and valley systems are carved. The pouring-out of this volcanic matter is not confined to the present time, or to late geologic time. Nor can the geologist assert that the rate of extravasation has increased or diminished from the earliest known geologic time to the present. It seems to have been paroxysmal by districts, but uniform, considering the whole extent of the surface of the earth. The magnitude of the volcanic formations exposed at the surface is such that the origin of the material cannot be attributed to local and trivial causes: it must be explained by laws of universal application. Extravasation is always associated, so far as the phenomena have been studied, with displacement; and this association is of such a nature that they must have a common explanation. This common explanation, as postulated by geologists, is a fluid interior.

\section{The argument from internal temperature.}

The hypothesis of a fluid interior is reached by another inductive method, - through the facts relating to increase of temperature from the surface downward. The rate of increase is not well known; it seems to be greatly variable. In general, it may be roughly stated, as it is by Thomson and Tait, as about one degree for each fifty feet; but in many cases the rate is much higher. Such an increase, known to extend so far down as observation and experiment have reached, if continued at the same rate, would soon give a temperature at which all known rocks would be melted; and the hypothesis of a fluid condition is thereby strengthened.

\section{The argument from the 'flow of solids.'}

It is an hypothesis worthy of consideration, that pressure itself would reduce the interior of the earth to a fluid condition. That rigidity, which is the characteristic of the solid state, is due to molecular cohesion; but geologists ever $y$ where in their researches discover that this molecular cohesion, or rigidity, may be overcome by pressure: for everywhere they find that rocks may be squeezed into new forms, bent, contorted, and implicated; that is, the force of compression existing in many thousands of feet of superincumbent rock overcomes molecular cohesion to such an extent as to cause rocks to yield (the molecular cohesion is broken down). Doubtless the element of time is involved, to some extent, as a rock may be bent with a small force, if sufficient time be allowed. But with increase of force there may be decrease of time; and the force engaged in compression, being the weight of miles of superincumbent rock, must be sufficient to greatly reduce the element of time, and perhaps to cause it to disappear. The last few years of experiment have added to the argument derived from geologic observation. Many solids have already been found to flow under pressure. The molecular constitution of solids is found to undergo a change by reason of pressure, so that new compounds may be formed thereby; and in pressure we have conditions for chemical change analogous to the conditions produced by melting. It is therefore an inductive hypothesis of the highest value, that all rocks may be reduced to a fluid condition - i.e., be caused to behave as bodies of minute parts, without rigidity of structure - by pressure alone.

The facts of observation and experiment characterized' above are vastly multifarious and cumulative, and the conclusions in each case are strictly inductive. The theory reached by the consilience of these four inductive processes is so strong, that structural geologists are compelled to accept it, and contradictory conclusions are rejected. It therefore behooves the physicist to re-examine his data and his methods of logical procedure ; for, perchance, he may discover that an error lurks therein.

J. W. Poweli.

\section{INERTIA.}

RECENT conversations with teachers of physics have shown me that there exists, in this country at least, great diversity of opinion as to the proper definition and use of the term 'inertia.'

Elementary text-books usually speak of inertia as a mere inability, - the inability of a body to set itself in motion, or to stop itself when once in motion. This is an old use of the term, but certainly not the best use. Maxwell states, ${ }^{1}$ that at the revival of science, " while the men of science understood by this term [the inertia of matter] the tendency of the body to persevere in its state of motion (or rest), and considered it a measurable quantity [the Italics are mine], those philosophers who were unacquainted with science understood inertia in its literal sense as a quality - mere want of activity, or laziness."

Maxwell suggests certain simple experiments 1 Theory of heat, p. 86. 